
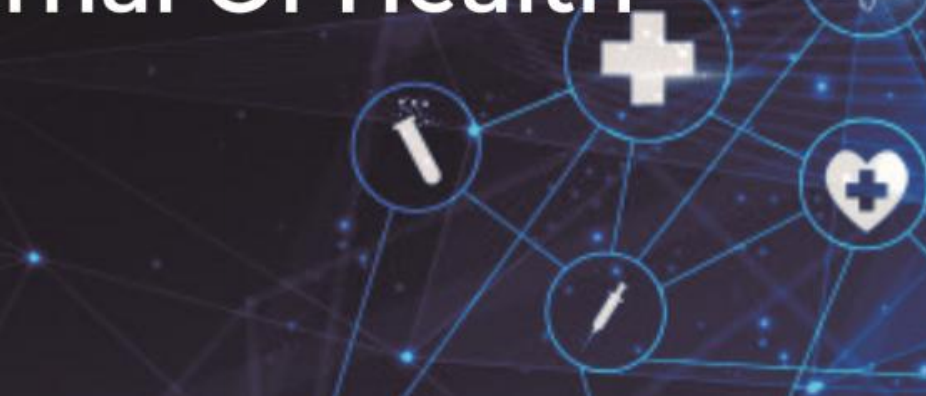

ARTIKEL RISET

http://inajoh.org/index.php/INAJOH/articel

\title{
Karakteristik Pasien Hipertensi di Puskesmas Tabaringan Makassar
}

\author{
Tenri Risna Abdi \\ ${ }^{1}$ Mahasiswa Pendidikan Dokter, Fakultas Kedokteran, Universitas Muslim Indonesia \\ Email Penulis Korespondensi: risnatenri@gmail.com
}

(08529900032)

\begin{abstract}
ABSTRAK
Hipertensi didefinisikan sebagai keadaan dimana tekanan darah sistolik (TDS) $\geq 140 \mathrm{mmHg}$ atau tekanan darah diastolik (TDD) $\geq 90 \mathrm{mmHg}$ yang diukur oleh tenaga kesehatan minimal dua kali pengukuran. Tujuan penelitian untuk mengetahui gambaran karakteristik pasien Hipertensi di Puskesmas Tabaringan. Karakteristik yang dimaksud berupa jenis kelamin, usia, IMT, dan derajat hipertensi. Metode penelitian yang dilakukan adalah penelitian deskriptif dengan menggunakan pendekatan observasional untuk melihat gambaran karakteristik pasien hipertensi di puskesmas tabaringan. Hasil penelitian menunjukkan banyaknya pasien laki - laki dengan hipertensi yaitu 34 orang $(44,7 \%)$ dan pasien perempuan sebanyak 42 orang $(55,3 \%)$. Diketahui bahwa jumlah pasien dewasa dengan interval usia 26 - 45 tahun yaitu 10 orang $(13,2 \%)$ dan pasien lansia dengan interval usia >45 tahun sebanyak 66 orang $(85,8 \%)$. Jumlah pasien hipertensi dengan IMT yang normal sebanyak 16 orang $(21,1 \%)$, overweight sebanyak 27 orang $(35,5 \%)$, obesitas I sebanyak 29 orang $(38,2 \%)$, dan obesitas II sebanyak 4 orang $(5,2 \%)$. Dapat diketahui bahwa jumlah pasien dengan derajat hipertensi normal (setelah rutin melakukan pengobatan) yaitu 7 orang $(9,2 \%)$, pre-hipertensi sebanyak 22 orang $(28,9 \%)$, hipertensi grade I sebanyak 39 orang $(51,3 \%)$ dan pasien dengan derajat hipertensi grade II sebanyak 8 orang $(10,6 \%)$. Kesimpulannya yaitu jenis kelamin pada penderita hipertensi didapatkan jumlah pasien wanita lebih banyak dibandingkan pasien laki-laki, usia penderita hipertensi didapatkan > 45 tahun atau termasuk dalam kategori lanjut usia, IMT penderita dengan status gizi overweight jauh lebih banyak dibandingkan status gizi yang lainnya, derajat hipertensi penderita lebih banyak jumlahnya pada hipertensi grade 1 .
\end{abstract}

Kata Kunci : : Hipertensi; Karakteristik, Puskesmas

\section{PUBLISHED BY :}

Yayasan Citra Cendekia Celebes

Address :

Perumahan Bukit Tamalanrea Permai

Blok D No.61 Kota Makassar,

Sulawesi Selatan, Kode Pos : 90211

Email : inajoh@inajoh.org

Phone : 082346913176
Article history : (dilengkapi oleh admin)

Received 09 Januari 2021

Received in revised form 20 Januari 2021

Accepted 09 Februari 2021

Available online 26 Februari 2021

licensed by Creative Commons Attribution-ShareAlike 4.0 International License. 


\section{ABSTRACT}

Hypertension is a condition which systolic blood pressure (TDS) $\geq 140 \mathrm{mmHg}$ or diastolic blood pressure (TDD) $290 \mathrm{mmHg}$ that measured by health personnel at least two times. The research Objective is to describe the characteristics of hypertensive patients at Tabaringan Health Center. The characteristics referred to gender, age, BMI, and hypertension degree. This research used descriptive research method by using an observational approach to describe the characteristics of hypertensive patients. The results showed that the total number of male patients with hypertension was 34 (44.7\%) and female patiens was 42 (55.3\%). It found that the number of patients with an age interval of 26 - 45 years was 10 (13.2\%) and the number of elderly patients with an age interval> 45 years was 66 (85.8\%). The number of hypertensive patients with normal BMI was 16 people (21.1\%), overweight were 27 people (35.5\%), obesity I was 29 people (38.2\%), and obesity II was 4 people $(5,2 \%)$. It can be seen that the number of patients with a normal degree of hypertension (after routine treatment) was 7 people (9.2\%), 22 people with pre-hypertension (28.9\%), 39 people with grade I hypertension (51, 3\%) and patients with grade II hypertension were 8 people (10.6\%). The conclusion is that the gender of hypertensive patients, the number of female patients is more prevalent than male patients, the age of hypertension patients is $>45$ years or is included in the elderly category, BMI in patients with overweight nutritional status is much more prevalent than others, and the degree of hypertension in patients was higher in grade 1 hypertension.

Keywords: Hypertension; Characteristics, Health center

\section{PENDAHULUAN}

Hipertensi dikategorikan sebagai the silent disease karena penderita tidak mengetahui dirinya mengidap hipertensi sebelum memeriksakan tekanan darahnya. ${ }^{1}$ Hipertensi tidak memberikan keluhan khas. Keluhan seperti tengkuk pegal atau pusing bisa disebabkan oleh gangguan lain. Oleh karena itu, penderita hipertensi tidak sadar bahwa dia menderita hipertensi, sehingga tidak memeriksakan diri atau tidak patuh berobat. ${ }^{2,3}$ Hipertensi adalah masalah kesehatan serius yang dimana secara signifikan meningkatkan resiko penyakit pada jantung, otak, dan penyakit lain. ${ }^{4}$

Semakin meningkatnya umur harapan hidup (UHH) menyebabkan bertambahnya jumlah lanjut usia (lansia). Hal ini dapat menimbulkan perubahan pola penyakit, dari penyakit infeksi menjadi penyakit degeneratif seperti hipertensi. ${ }^{1,5}$ Menurut laporan Badan Pusat Statistik (BPS) terjadi peningkatan UHH dari 69,43 tahun pada tahun 2010 menjadi 69,65 tahun pada tahun 2011 dengan persentase populasi lansia adalah 7,58\% dari total penduduk Indonesia. Lansia perempuan lebih banyak daripada laki-laki. ${ }^{5}$ Pada umumnya pria lebih banyak menderita hipertensi dibandingkan dengan perempuan, dengan rasio sekitar 2,29\% untuk peningkatan tekanan darah sistolik. ${ }^{6}$ Jenis keluhan yang paling banyak dialami lansia terkait dengan penyakit kronis, seperti asam urat, darah tinggi, rematik, darah rendah dan diabetes. Penyakit yang paling banyak diderita oleh pasien rawat jalan dalam kelompok usia 45-64 tahun dan di atas 65 tahun adalah hipertensi ${ }^{5}$.

Sampai saat ini hipertensi masih merupakan tantangan besar di Indonesia, betapa tidak, hipertensi merupakan kondisi yang sering ditemukan pada pelayanan kesehatan primer kesehatan. Hal itu merupakan masalah kesehatan dengan prevalensi yang tinggi, yaitu sebesar $34,1 \%$, sesuai dengan data Riskesdas 2018. Di samping itu, pengontrolan hipertensi belum adekuat meskipun obat-obatan yang efektif banyak tersedia. ${ }^{7}$

Menurut WHO sekitar 1,13 milyar manusia di seluruh dunia memiliki hipertensi, dan umumnya (dua per tiga) tinggal pada negara dengan penghasilan rendah dan sedang. ${ }^{4}$ Menurut the International 
Society of Hypertension (ISH) diperkirakan sekitar $80 \%$ kenaikan kasus hipertensi terutama di negara berkembang tahun 2025, dari sejumlah 639 juta kasus di tahun 2000, di perkirakan menjadi 1,15 milyar kasus di tahun 2025. Prediksi ini didasarkan pada angka penderita hipertensi saat ini dan pertambahan penduduk saat ini. Hal ini diperparah dengan 7 dari setiap 10 penderita tersebut tidak mendapatkan pengobatan secara adekuat. ${ }^{8,9}$

Di Indonesia, hipertensi didapatkan pada 83 per 1000 anggota rumah tangga. Prevalensi tekanan darah tinggi meningkat dengan seiring dengan peningkatan usia. Banyaknya penderita hipertensi diperkirakan 15 juta orang tetapi hanya 4\% yang merupakan hipertensi terkontrol. Prevalensi 6-15\% pada orang dewasa, 50\% diantaranya tidak menyadari sebagai penderita hipertensi sehingga mereka cenderung untuk menjadi hipertensi berat karena tidak menghindari dan tidak mengetahui faktor risikonya, dan $90 \%$ merupakan hipertensi esensial. Hal itu merupakan masalah kesehatan dengan prevalensi yang tinggi, yaitu sebesar 25,8\%, sesuai dengan data Riskesdas 2013. Di Sulawesi Selatan sendiri penderita hipertensi terdapat kurang lebih $29 \%$ dari total penduduk yang ada. Angka ini akan terus bertambah apabila tidak diimbangi dengan edukasi dan terapi hipertensi yang adekuat ${ }^{9-}$ 11

Beberapa studi menunjukkan bahwa seseorang yang mempunyai kelebihan berat badan lebih dari $20 \%$ dan hiperkolesterol mempunyai risiko yang lebih besar terkena hipertensi. Terkait terjadinya aterosklerosis dalam pembuluh darah, sehingga menyebabkan semakin tinggi resistensi vascular sistemik dan memicu kepada peningkatan tekanan darah yang lebih berat. ${ }^{8,12,13}$ Faktor risiko tersebut pada umumnya disebabkan pola hidup (life style) yang tidak sehat seperti merokok, minum minuman beralkohol, kurang aktivitas fisik, dan konsumsi garam yang berlebihan. ${ }^{14}$

Terapi farmakologic cukup penting dalam mencapai target ini, tetapi modifikasi asupan makanan sehari-hari merupakan salah satu bagian modifikasi gaya hidup yang mempunyai peran yang besar dalam mencegah kenaikan tekanan darah pada individu yang tidak menderita hipertensi, serta menurunkan tekanan darah pada prehipertensi dan penderita hipertensi. Dewasa ini berbagai penelitian menunjukkan beberapa zat gizi, bahan makanan tertentu, pola asupan makanan sehari-hari/diet berperan dalam pencegahan dan terapi hipertensi. ${ }^{2,3}$

Salah satu pemicu praktik gaya hidup pasien yang rentan terhadap sebagian faktor risiko kejadian hipertensi adalah kurangnya pengetahuan dan kesadaran mereka tentang pentingnya informasi kesehatan seputar masalah hipertensi dan perilaku untuk menghindari faktor risiko hipertensi.

\section{METODE}

Penelitian yang dilakukan adalah penelitian deskriptif dengan menggunakan pendekatan observasional untuk melihat gambaran karakteristik pasien hipertensi di Puskesmas Tabaringan. Lokasi penelitian yang dipilih adalah di Puskesmas Tabaringan. Penelitian ini akan dilaksanakan pada bulan Agustus 2019. Sampel pada penelitian ini yaitu pasien dengan hipertensi di Puskesmas 
Tabaringan yang berjumlah 76 orang. Kriteria sampel pada penelitian ini yaitu pasien dengan hipertensi, terdaftar sebagai pasien rujuk balik di Puskesmas Tabaringan, telah mendapat diagnosa keluar pada resume medis oleh dokter dengan hipertensi, telah mendapatkan terapi farmakologi yang tertera pada catatan terintegrasi dalam rekam medik. Kriteria objektif penelitian ini terbagi menjadi dua yaitu, hipertensi grade 1 dengan dikatakan hipertensi grade 1 jika penderita memiliki tekanan darah sistolik $\geq 140$ - $159 \mathrm{mmHg}$ dan/atau tekanan darah diastolik $\geq 90$ - $99 \mathrm{mmHg}$, dan hipertensi grade 2 yang dikatakan hipertensi grade 2 jika penderita memiliki tekanan darah sistolik $\geq 160 \mathrm{mmHg}$ dan/atau tekanan darah diastolik $\geq 100 \mathrm{mmHg}$. Dalam penelitian ini, instrumen yang digunakan adalah data rekam medik pasien hipertensi di Puskesmas Tabaringan. Pengolahan data dilakukan secara elektronik dengan menggunakan perangkat lunak komputer program Microsoft Excel 2007 dan SPSS 22. Sedangkan penyajian data menggunakan tabel distribusi frekuensi presentasi disertai dengan penjelasan tabel.

\section{HASIL}

Karakteristik sampel berikut ini menjelaskan mengenai distribusi frekuensi dari setiap variabel terkait mengenai jenis kelamin, usia, IMT, dan derajat hipertensi di Puskesmas Tabaringan. Adapun hasil analisis data tersebut sebagai berikut:

Tabel 1. Distribusi frekuensi pasien hipertensi berdasarkan jenis kelamin

\begin{tabular}{ccc}
\hline Interval Usia & Frekuensi & Persentase \\
\hline Laki-Laki & 34 & $44,7 \%$ \\
Perempuan & 42 & $55,3 \%$ \\
\hline Total & 76 & $100 \%$
\end{tabular}

Berdasarkan Tabel 5.1 dapat diketahui bahwa jumlah jumlah pasien laki - laki dengan hipertensi yaitu berjumlah 34 orang $(44,7 \%)$ dan jumlah pasien perempuan dengan hipertensi yaitu berjumlah 42 orang $(55,3 \%)$.

Table 2. Distribusi frekuensi pasien hipertensi berdasarkan usia

\begin{tabular}{ccc}
\hline Jenis Kelamin & Frekuensi & Persentase \\
\hline Remaja (12-25 tahun) & 0 & $0 \%$ \\
Dewasa (26-45 tahun) & 10 & $13,2 \%$ \\
Lansia (>45 tahun) & 66 & $85,8 \%$ \\
\hline Total & 76 & $100 \%$ \\
\hline
\end{tabular}

Berdasarkan Tabel 5.2 dapat diketahui bahwa jumlah pasien remaja dengan interval usia 12 - 25 tahun yaitu berjumlah 0 orang $(0 \%)$. Jumlah pasien dewasa dengan interval usia 26 - 45 tahun yaitu berjumlah 10 orang $(13,2 \%)$ dan jumlah pasien lansia dengan interval usia $>45$ tahun yaitu berjumlah 66 orang $(85,8 \%)$. 
Table 3. Distribusi frekuensi pasien hipertensi berdasarkan IMT

\begin{tabular}{ccc}
\hline IMT & Frekuensi & Persentase \\
\hline Normal & 16 & $21,1 \%$ \\
Overweight & 29 & $38,2 \%$ \\
Obesitas I & 27 & $35,5 \%$ \\
Obesitas II & 4 & $5,2 \%$ \\
\hline Total & 76 & $100 \%$ \\
\hline
\end{tabular}

Berdasarkan Tabel 5.3 dapat diketahui bahwa jumlah pasien hipertensi dengan IMT yang normal sebanyak 16 orang $(21,1 \%)$, overweight sebanyak 27 orang (35,5\%), obesitas I sebanyak 29 orang $(38,2 \%)$, dan obesitas II sebanyak 4 orang $(5,2 \%)$.

Table 4. Distribusi frekuensi pasien hipertensi berdasarkan derajat hipertensi

\begin{tabular}{ccc}
\hline Derajat Hipertensi & Frekuensi & Persentase \\
\hline Normal & 7 & $9,2 \%$ \\
Pre-hipertensi & 22 & $28,9 \%$ \\
Hipertensi Grade I & 39 & $51,3 \%$ \\
Hipertensi Grade II & 8 & $10,6 \%$ \\
\hline Total & 76 & $100 \%$ \\
\hline
\end{tabular}

Berdasarkan Tabel 5.4 dapat diketahui bahwa jumlah pasien dengan derajat hipertensi normal (setelah rutin melakukan pengobatan) yaitu berjumlah 7 orang $(9,2 \%)$, pre-hipertensi yaitu berjumlah 22 orang $(28,9 \%)$, hipertensi grade I yaitu berjumlah 39 orang $(51,3 \%)$ dan pasien dengan derajat hipertensi grade II yaitu berjumlah 8 orang $(10,6 \%)$.

\section{PEMBAHASAN}

Berdasarkan jenis kelamin, pasien hipertensi wanita lebih banyak $(55,3 \%)$ dibandingkan pria $(44,7 \%)$. Hasil ini sejalan dengan penelitian sebelumnya dimana persentase hipertensi pada wanita lebih besar yaitu $61.2 \%$ setelah menopause. ${ }^{15}$ Disebutkan bahwa sebelum usia 45 tahun pria lebih banyak menderita hipertensi dan setelah usia 45 tahun wanita lebih banyak menderita hipertensi karena telah mengalami menopause. Pada wanita yang obesitas dan menggunakan kontrasepsi oral lebih tinggi risiko untuk menderita hipertensi. ${ }^{15}$ Wanita yang belum mengalami menopause dilindungi oleh hormon estrogen yang berperan dalam meningkatkan kadar High Density Lipoprotein (HDL). ${ }^{16}$

Berdasarkan hasil penelitian menunjukkan bahwa persentase pasien hipertensi meningkat sesuai dengan meningkatnya umur. Dari hasil penelitian, usia > 45 tahun merupakan persentase hipertensi terbanyak dibandingkan dengan usia dibawahnya, yaitu sebesar 85,8 \%. Data dari Riskesdas tahun 
2007 juga mendukung hasil penelitian ini dimana usia 60 tahun ke atas kejadian hipertensi semakin meningkat. ${ }^{6}$ Tekanan darah cenderung meningkat dengan bertambahnya usia. Pada laki-laki meningkat pada usia lebih dari 45 tahun sedangkan pada wanita meningkat pada usia lebih dari 55 tahun. ${ }^{17}$ Semakin tua usia seseorang maka pengaturan metabolisme zat kapur (kalsium) terganggu. ${ }^{18}$ Hal ini menyebabkan banyaknya zat kapur yang beredar bersama aliran darah. Akibatnya darah menjadi lebih padat dan tekanan darah pun meningkat. ${ }^{19}$

Berdasarkan IMT, pasien hipertensi dengan status gizi overweight lebih banyak yaitu 38,2 \% dibandingkan yang normal karena obesitas merupakan salah satu faktor risiko terjadinya hipertensi berkaitan dengan penumpukan lemak yang bisa saja terjadi di lumen pembuluh darah dan memudahkan terjadinya vasokonstriksi pada vaskuler. ${ }^{20}$ Obesitas dapat menyebabkan hipertensi dan penyakit kardiovaskular dengan mengaktifkan sistem renin-angiotensin-aldosteron, dengan meningkatkan aktivitas simpatis, dengan meningkatkan resistensi insulin dan resistensi leptin, dengan peningkatan aktivitas prakoagulasi dan disfungsi endotel. ${ }^{21}$ Mekanisme lebih lanjut termasuk peningkatan reabsorbsi natrium ginjal, menyebabkan pergeseran hubungan tekanan-natriuresis dan mengakibatkan ekspansi volume. ${ }^{22}$ Obesitas kronis juga menyebabkan perubahan struktural pada ginjal yang menyebabkan hilangnya fungsi nefron, yang selanjutnya meningkatkan tekanan darah. ${ }^{23}$

Hipertensi grade 1 merupakan persentase yang lebih banyak, yaitu 51,3\%. Hal ini dikarenakan sebagian besar sampel telah menjalani pengobatan hipertensi yang cukup lama namun tidak terkontrol. Pada tatalaksana hipertensi tahap 1, periode pengamatan tiga sampai enam bulan dianjurkan kecuali, keterlibatan organ target sudah jelas. ${ }^{24}$ Bila setelah jangka waktu tersebut, tidak didapatkan penurunan tekanan darah yang diharapkan atau didapatkan faktor risiko kardiovaskular yang lain, maka sangat dianjurkan untuk memulai terapi farmakologi. ${ }^{25}$

\section{KESIMPULAN DAN SARAN}

Dari penelitian ini dapat disimpulkan bahwa karakteristik jenis kelamin pada penderita hipertensi didapatkan jumlah pasien wanita lebih banyak dibandingkan pasien laki-laki, karakteristik usia pada penderita hipertensi didapatkan jumlah pasien usia $>45$ tahun atau termasuk dalam kategori lanjut usia jauh lebih banyak dibandingkan usia di bawahnya, karakteristik IMT pada penderita hipertensi didapatkan jumlah pasien dengan status gizi overweight jauh lebih banyak dibandingkan status gizi yang lainnya, dan derajat hipertensi pada penderita hipertensi didapatkan lebih banyak jumlahnya pada hipertensi grade 1. Saran penelitian ini agar dapat meningkatkan kondisi yang telah dicapai saat ini yaitu Puskesmas yang memiliki tingkat yang dapat dikategorikan dalam penilaian yang baik, puskesmas harus meningkatkan mutu pelayanan kesehatan dengan lebih menuliskan secara lengkap rekam medik pasien agar mempermudah peneliti selanjutnya dalam mengumpulkan sampel penelitian. 


\section{DAFTAR PUSTAKA}

1. Sugiharto A, Hadisaputro S, Adi S, Chasani S. Faktor-Faktor Risiko Hipertensi Grade II Pada Masyarakat ( Studi Kasus di Kabupaten Karanganyar ) Risk Factors of Grade II Hypertension in Community ( Case Study at Karanganyar District ) PDF created with pdfFactory Pro trial version www.pdffactory.com Fa. Ratio. 2007;26. http://eprints.undip.ac.id/5265/

2. Rilantono LL. 5 Rahasia Penyakit Kardiovaskuler. Badan Penerbit Fakultas Kedokteran Ui; 2015.

3. Benson H. Menurunkan Tekanan Darah. Published online 2012.

4. World Health Organization. Hypertension. Published online 2019. https://www.who.int/newsroom/fact-sheets/detail/hypertension

5. Harjatmo TP, Par'i HM, Wiyono S. Penilaian Status Gizi. In: Bahan Ajar Gizi. Kementerian Kesehatan Republik Indonesia; 2017:315.

6. Depkes. Laporan Nasional Riskesdas 2007. Badan Penelit dan Pengemb Kesehat Dep Kesehatan, Republik Indones Desember 2008. Published online 2008:1-384. http://kesga.kemkes.go.id/images/pedoman/Riskesdas 2007 Nasional.pdf

7. Kementerian Kesehatan Republik Indonesia. Hipertensi Penyakit Paling Banyak Diidap Masyarakat. Kemenkes RI. Published online 2019.

8. Rahajeng E, Tuminah S. Prevalensi Hipertensi dan Determinannya di Indonesia. Maj Kedokt Indones. 2009;59:580-587.

9. Armilawaty Amirudin R AH. Hipertensi dan Faktor Risikonya dalam Kajian Epidemiologi. Bagian Epidemiologi FKM UNHAS. 2007;2014(2 juni 2014):1-6.

10. Appel LJ, Brands MW, Daniels SR, Karanja N, Elmer PJ, Sacks FM. Dietary Approaches to Prevent and Treat Hypertension: A Scientific Statement from the American Heart Association. Vol 47.; 2006. doi:10.1161/01.HYP.0000202568.01167.B6

11. Ridjab D a. Modifikasi Gaya Hidup dan Tekanan Darah. Maj Kedokt Indones. 2007;57:159166.

12. Huon H G. Kardiologi. Published online 2005:290.

13. Dokter P, Kardiovaskular S PE. Pedoman tatalaksana hipertensi pada penyakit kardiovaskular. Published online 2015.

14. Shikha Singh, Ravi Shankar GPS. Prevalence and Associated Risk Factors of Hypertension: A Cross-Sectional Study in Urban Varanasi. Int J Hypertens. Published online 2017.

15. Price SA, Wilson LM. Patofisiologi : Konsep Klinis Proses-Proses Penyakit / Sylvia A. Price; Lorraine M. Wilson. EGC; 2005.

16. Dwi L PY. Faktor-faktor yang berhubungan dengan tingkat hipertensi di wilayah kerja puskesmas demak. Published online 2016:67.

17. GY A. Korelasi Derajat Hipertensi dengan Stadium Penyakit Ginjal Kronik di RSUP dr. Kariadi Semarang Periode 2008-2012. Published online 2013.

18. Chobanian. The Seventh Report of the Joint National Committee on Prevention, Detection, Evaluation, And Treatment of High Blood Pressure (JNC-VII). Jama. Published online 2003:2560-257.

19. Elperin DT, Pelter MA, Deamer RL, Burchette RJ. A Large Cohort Study Evaluating Risk Factors Associated With Uncontrolled Hypertension. J Clin Hypertens. 2014;16(2):149-154. doi:10.1111/jch.12259

20. Vaněčková I, Maletínská L, Behuliak M, Nagelová V, Zicha J, Kuneš J. Obesity-related hypertension: Possible pathophysiological mechanisms. J Endocrinol. 2014;223(3):R63-R78. doi:10.1530/JOE-14-0368

21. Hall JE, Do Carmo JM, Da Silva AA, Wang Z, Hall ME. Obesity-Induced Hypertension: Interaction of Neurohumoral and Renal Mechanisms. Circ Res. 2015;116(6):991-1006. doi:10.1161/CIRCRESAHA.116.305697

22. Jiang SZ, Lu W, Zong XF, Ruan HY, Liu Y. Obesity and hypertension. Exp Ther Med. 2016;12(4):2395-2399. doi:10.3892/etm.2016.3667

23. Aronow WS. Association of obesity with hypertension. Ann Transl Med. 2017;5(17):11-13. doi:10.21037/atm.2017.06.69 
24. James PA, Oparil S, Carter BL, et al. 2014 Evidence-based guideline for the management of high blood pressure in adults: Report from the panel members appointed to the Eighth Joint National Committee (JNC 8). JAMA - J Am Med Assoc. 2014;311(5):507-520. doi:10.1001/jama.2013.284427

25. Wang $\mathrm{HH}$, Wong MC, Mok RY, et al. Factors associated with grade 1 hypertension: Implications for hypertension care based on the Dietary Approaches to Stop Hypertension (DASH) in primary care settings. BMC Fam Pract. 2015;16(1):1-10. doi:10.1186/s12875-015$0239-4$ 